\title{
Workhardening Behaviour and Microstructural Analysis of Failed Austenitic Manganese Steel Crusher Jaws
}

\author{
Olawale J. O.*, Ibitoye S. A., Shittu M. D. \\ Department of Materials Science and Engineering, Obafemi Awolowo University Ile-Ife, Nigeria
}

Received: October 9, 2012; Revised: April 26, 2013

\begin{abstract}
This study focussed on the work hardening behaviour and microstructure of austenitic manganese steel relative to premature failure of crusher jaws. Samples of sound and failed crusher jaws were taken, the change with depth from the working surface to the sample core was measured and their microstructures observed. The study revealed a sharp hardness gradient in the failed crusher jaws, and presence of large carbides at both the austenite grain boundaries and in the austenite matrix. The failure of crusher jaws was attributed to brittle fracture as a result of precipitates of carbides from the inability of precipitated carbides to absorb shock during impact working. Finally, we conclude that the failure occurred as a result of inadequate quenching operations during the manufacturing process that resulted in the formation of carbide precipitates which embrittle the austenitic manganese steel, reduce its ability to withstand shock and create a non uniform plastic flow as it is work hardening.
\end{abstract}

Keywords: brittle fracture, carbides, embrittlement, grain boundary, microstructure

\section{Introduction}

Austenitic manganese steel, also called Hadfield steel, after its inventor Sir Robert Hadfield who patented the steel in 1882, has the chemical composition of $1.2 \% \mathrm{C}$ and $12 \% \mathrm{Mn}$. This alloy possesses unique resistance to impact and abrasion wear. It exhibits high levels of ductility and toughness and slow crack propagation rates, in comparison to other potentially competitive materials. It is also nonmagnetic and can work harden during service or can be surface-hardened to as high as $450 \mathrm{HB}$ by mechanical or explosive means prior to service ${ }^{1,2}$.

Hadfield steels have the ability to harden in-depth in service as well as by induced means. Work hardening is usually induced by impact, as from hammer blows. Light blows, even if they are of high velocity, cause shallow deformation with only superficial hardening even though the resulting surface hardness is ordinarily high. Heavy impact produces deeper hardening; usually with lower values of surface hardness ${ }^{3}$. Manganese steels are unequalled in their ability to harden, exceeding even the metal stable austenitic stainless steels. For example, standard grades of manganese steel containing 1.0 to $1.4 \% \mathrm{C}$ and 10 to $14 \%$ Mn can work harden from initial of $220 \mathrm{Hv}$ to a maximum of more than $900 \mathrm{Hv}^{4-6}$.

Indeed Hadfield steel is a remarkable engineering alloy which in fully solutionized form is soft and ductile but when deformed, it work hardens rapidly. Work hardening mechanisms, impact wear, abrasive wear and the alloying of austenitic manganese steel have been investigated by several researchers and results have shown that under repeated impact and abrasive wear it work hardens rapidly and displays remarkable toughness ${ }^{7-21}$. Several other works on its surface treatment have also proved that surface treatment

*e-mail: jooolawale@yahoo.com increases its surface hardness and wear resistance $22-25$. However, the rate of work hardening depends primarily on the amount of carbon in solution in the austenite matrix and the presence of a fine dispersion of carbides. The presence, amount and dispersion of carbides significantly influence the wear resistance of the alloy and, if the carbides form interconnected grain boundary films they seriously impair the impact strength ${ }^{8}$. The embrittling intergranular carbides are formed during solidification because of a slow rate of cooling or precipitation during reheating at a temperature range of $400{ }^{\circ} \mathrm{C}-800{ }^{\circ} \mathrm{C}^{[26]}$.

The embrittling carbides present in as-cast structure are removed by solution treatment and quenching. A common industrial practice is to heat treat the material at high temperature, soaks for one hour per $25 \mathrm{~mm}$ thickness, and followed by water quenching. It has been found that treatment temperature in the range of $950{ }^{\circ} \mathrm{C}$ to $1100{ }^{\circ} \mathrm{C}$ give required mechanical properties because this temperature range slightly influences grain size, stress limit and hardness of austenitic manganese steel. But treatment at temperatures higher than $1150{ }^{\circ} \mathrm{C}$ results in the growth of austenite grain size and the decrease of mechanical properties ${ }^{27}$. Also, it was found that the cooling rate during quenching period of heavy section is relatively low and the opportunity of carbide precipitate formation during the heat treatment increases ${ }^{28}$. Shabnam and Mohammad observed that enhancing quenching solution cooling rate, the precipitation of carbides will decrease and the austenite matrix will retains more carbon as soluble carbon after heat treatment operation ${ }^{29}$. So solution heat treatment carried out in the temperature range of $950{ }^{\circ} \mathrm{C}$ to $1050{ }^{\circ} \mathrm{C}$ and rapid quenching after the casting process will maintain the homogeneous austenitic structure. The resulting retained austenite structure with a 
large amount of carbon gives these steels their high impact toughness and high strain hardening rate capacity, which gives them their excellent impact abrasion resistance. Hence, solution treatment makes these steels very soft $(190 \mathrm{HB})$ and as noted earlier, impact deformation can increase its surface hardness even to about $500 \mathrm{HB}^{30}$.

From all these past works Hadfield steel is considered an alloy with inherent toughness, work hardening characteristics and excellent resistance to some types of adhesive and abrasive wears ${ }^{1-30}$. These unique properties of Hadfield steel therefore make it a suitable candidate material for the production of crusher jaws. However, it was reported that some of the crusher jaws used in crushing granite in Nigeria failed prematurely by fracturing across the teeth while some worn-out to paper thin. Hence, the current research studies the work hardening behaviour and microstructure of Hadfield steel that might lead to premature failure.

\section{Experimental Procedure}

One sample of sound crusher jaw (S) and four samples of failed crusher jaws $\left(\mathrm{F}_{1}, \mathrm{~F}_{2}, \mathrm{~F}_{3}\right.$ and $\left.\mathrm{F}_{4}\right)$ were selected for this study. The service conditions were evaluated, the chemical composition were analysed by spectrometer, the changes in the hardness with the increasing depth were measured using Houndsfield extensometer in compression mode, and the impact strengths were measured using Izod impact tests. The microstructures were then observed through metallographic techniques.

\subsection{Background information}

Information pertaining to the service conditions that presumably led to failure, prior manufacturing process, pertinent codes, specification, standard and the number of tonnage of rocks crushed before broken were collated. The method and pattern of loading were also critically observed.

\subsection{Chemical analysis}

Chemical composition was determined by spectrometric analysis using the spectrometer ARL 3460 model. Four cylindrical samples $\left(\mathrm{F}_{1}, \mathrm{~F}_{2}, \mathrm{~F}_{3}\right.$ and $\left.\mathrm{F}_{4}\right)$ of about $40 \mathrm{~mm}$ diameter each with $5 \mathrm{~mm}$ thickness were taken from failed crusher jaws and one sample (S) of the same dimension was taken from a sound crusher jaw. The selected samples were sparked inside the spectrometer and the resultant elemental compositions of each of the samples were taken.

\subsection{Measurement of hardness values}

The hardness attained at various depths from the working surface to the core of imported and locally produced crusher jaws were measured to determine the extent of plastic flow and work hardening under service conditions. The working surface of the samples were made a reference point $(0 \mathrm{~mm})$ and calibrated to equal distance of $10 \mathrm{~mm}$ along a direction perpendicular to their working surface towards the core of the sample, to a total distance of $120 \mathrm{~mm}$. The test was carried out by polishing the surface of the specimens to 600 microns, pressing a steel ball of $10 \mathrm{~mm}$ diameter against the polished surface with a load of
$3000 \mathrm{~kg}$ using a dwell time of 15 seconds on a Houndsfield extensometer. The diameter of the impression left by the ball was then measured using a Brinell calibrated hand lens and the corresponding Brinell hardness number was determined.

\subsection{Measurement of impact strength}

The impact strength of both the sound and failed samples of crusher jaws was measured using the Izod impact test method on a Houndsfield balance impact-testing machine as per. Five (5) samples of sound crusher jaw and five (5) samples each of failed crusher jaws were machined to $10 \mathrm{~mm} \times 10 \mathrm{~mm} \times 75 \mathrm{~mm}$ square cross sections and $\mathrm{V}$-notched (2-mm depth and included angle $45^{\circ}$ ) at $28 \mathrm{~mm}$ distance from one end, and then tested for impact strength. The amount of impact energy absorbed by each specimen before yielding was taken as a measurement of impact strength in Joules. The average values from the five test samples are reported here.

\subsection{Heat treatment}

Three specimens $(150 \mathrm{~mm} \times 150 \mathrm{~mm} \times 250 \mathrm{~mm}$ cubic shaped) were prepared by sand casting of $1.3 \% \mathrm{C}-0.6 \%$ $\mathrm{Mn}-13 \%$ Mn steel (grade B4) which represent the thickness of general crusher jaws ${ }^{4,31}$. Two of these specimens were solution heat treated. The specimens were heated up to $1050{ }^{\circ} \mathrm{C}$ for 11 hours, soaked for 10 hours at $1050{ }^{\circ} \mathrm{C}$, and rapidly quenched in water bath. Two different quenching operations were used; a specimen was rapidly quenched in water with agitation while the other in water without agitation.

\subsection{Microstructural analysis}

Samples for microstructural investigation were taken from S1, F1, F2, F3 and F4, as-cast specimen, and heat treated specimens. The samples were cut with a wire cutting machine to prevent the work hardening or phase transformation by heat effect during machining. Thereafter they were taken through metallographic techniques: mounting, flattening, grinding and polishing. The microstructures were then examined by optical microscopy after etching with $2 \frac{1}{2} \%$ nital solutions, rinsed in methanol and retched in $15 \% \mathrm{HCl}$. The fractions of resulting phases were measured using linear intercept method.

\section{Results and Discussion}

\subsection{Results}

From the evaluation of service conditions the crusher jaws are used in crushing machines for crushing of rocks into granites for road building and civil works. All crushers work with a pair of crusher jaws: fixed jaws and swing jaws. Both are fixed in a vertical position at the front end of a hollow rectangular frame. The swing jaw is moved against the fixed jaws under a high compressive force to break rocks into granules. Thus, the crusher jaws must be quite hard to crush rocks and also be tough enough to be able to absorb the impact energy generated by the swing jaws. 
The processing history of failed crusher jaws indicates that they were cast from grade B4, heat treated up to $1050^{\circ} \mathrm{C}$ and rapidly quenched in water bath without agitation.

The number of tonnage of rocks crushed by the crusher jaws selected for this study is presented in Figure 1. The results of the chemical composition tests of the sound crusher jaw $(\mathrm{S})$ and failed crusher jaws $\left(\mathrm{F}_{1}, \mathrm{~F}_{2}, \mathrm{~F}_{3}\right.$ and $\left.\mathrm{F}_{4}\right)$ are presented in Table 1. The Brinell hardnesses at various case depths are presented in Figure 2 to 5. The impact strengths for both sound and failed crusher jaws are presented in Figure 6.

The observed microstructures of the samples are shown in Figures 7 to 14 . Figures 7 and 12 shows austenite structure while Figures 8 to 13 show austenite structure with large carbide at the grain boundaries and in the grain. The carbide fraction in each sample is presented in Figure 15.

\subsection{Discussion}

Crusher jaws must combine both high toughness and good resistance to wear. This is the reasons why Hadfield steels that possess this unique resistance to impact and abrasion wears are used for its production. Hadfield steels

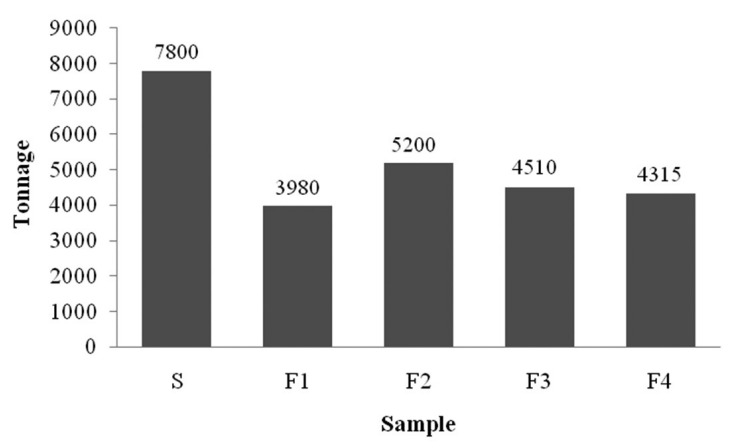

Figure 1. The number of tonnage of rocks crushed before failure. exhibit high levels of ductility and toughness and slow crack propagation rates, in comparison with other competitive materials ${ }^{4,32}$. Since austenitic manganese steels meet the requirements of service conditions the operating conditions might not be responsible for premature failure.

The chemical analysis of samples taken from the sound and failed crusher jaws revealed that their chemical compositions grade B4 (Table 1$)^{33}$. Hence, the premature fracture of the failed crusher jaws cannot be attributed to an incorrect chemical composition.

The microstructure of the sound crusher jaw sample revealed austenitic grains as shown in Figure 7. The black lines are austenite grain boundaries. However, all the samples taken from failed crusher jaws revealed either austenitic grains with large carbide at the grain boundaries or large carbide at the grain boundary and in the grain as shown in Figures 8 to 11. The dark greyish constituents are large carbides, which are at the grain boundaries and in the grain. These large carbides at the grain boundaries and in the grain caused the early fractures ${ }^{34,35}$.

The microstructure of as-cast sample revealed large carbide along the austenite grain boundaries (Figure 12) but

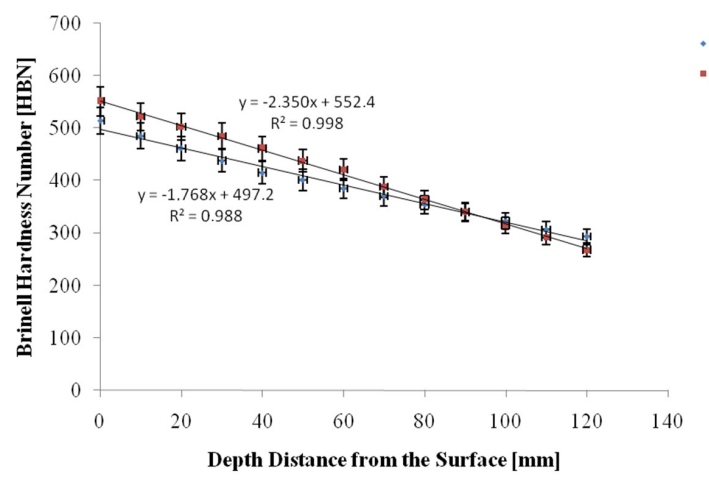

Figure 2. Hardness Value vs Depth for S and F1.

Table 1. Results of spectrometric analysis.

\begin{tabular}{cccccc}
\hline Element & Sample $\mathbf{S}$ & ${\text { Sample } \mathbf{F}_{\mathbf{1}}}$ & ${\text { Sample } \mathbf{F}_{\mathbf{2}}}$ & ${\text { Sample } \mathbf{F}_{\mathbf{3}}}^{\text {Sample }_{\mathbf{4}}}$ \\
\hline $\mathrm{Fe}$ & Balance & Balance & Balance & Balance & Balance \\
$\mathrm{C}$ & 1.355 & 1.280 & 1.250 & 1.275 & 1.250 \\
$\mathrm{Mn}$ & 12.90 & 12.10 & 12.70 & 0.950 & 11.50 \\
$\mathrm{Si}$ & 0.850 & 0.555 & 0.650 & 0.050 & 0.600 \\
$\mathrm{P}$ & 0.050 & 0.060 & 0.060 & 0.001 & 0.045 \\
$\mathrm{~S}$ & 0.004 & 0.005 & 0.002 & 0.013 & 0.007 \\
$\mathrm{Cr}$ & 0.013 & 0.058 & 0.011 & 0.018 & 0.015 \\
$\mathrm{Ni}$ & 0.022 & 0.020 & 0.019 & 0.022 & 0.021 \\
$\mathrm{Cu}$ & 0.012 & 0.013 & 0.012 & 0.034 & 0.020 \\
$\mathrm{Mo}$ & 0.052 & 0.032 & 0.056 & 0.005 & 0.027 \\
$\mathrm{~V}$ & 0.020 & 0.088 & 0.007 & 0.019 & 0.018 \\
$\mathrm{Ti}$ & 0.007 & 0.015 & 0.005 & 0.050 & 0.012 \\
$\mathrm{Al}$ & 0.050 & 0.050 & 0.050 & 0.005 & 0.050 \\
$\mathrm{Mg}$ & 0.005 & 0.005 & 0.005 & 0.018 & 0.005 \\
$\mathrm{Sn}$ & 0.015 & 0.013 & 0.018 & 0.016 & 0.022 \\
$\mathrm{As}$ & 0.006 & 0.013 & 0.020 & 0.050 & 0.017 \\
$\mathrm{Co}$ & 0.050 & 0.050 & 0.050 & 0.050 & 0.050 \\
$\mathrm{~W}$ & 0.050 & 0.050 & 0.050 & 0.050 \\
\hline
\end{tabular}




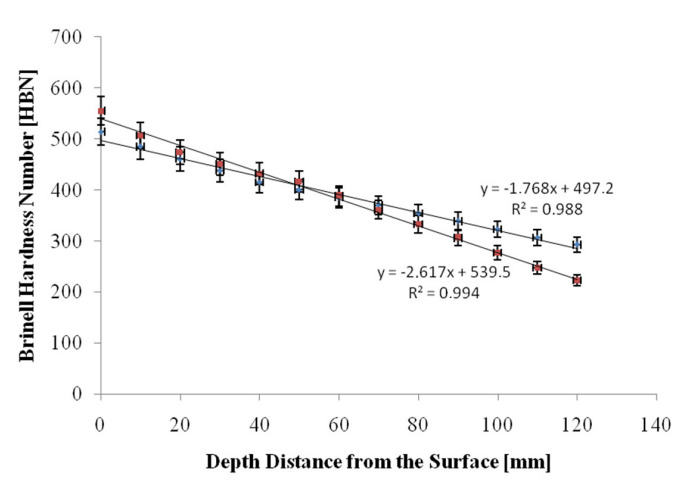

Figure 3. Hardness Value vs Depth for S and F2.

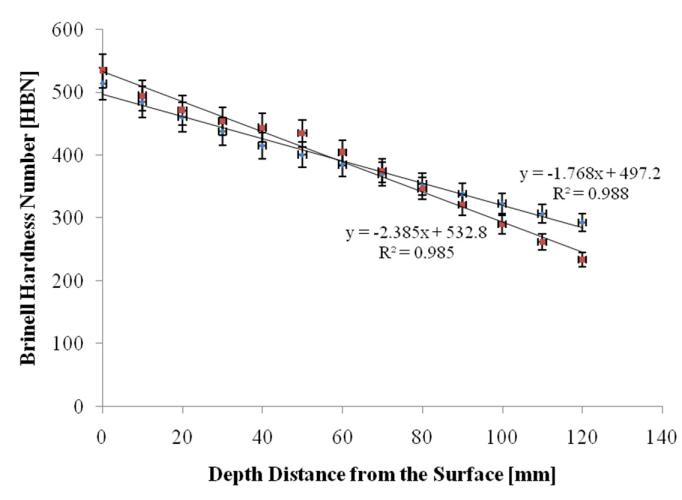

Figure 4. Hardness Value vs Depth for S and F3.

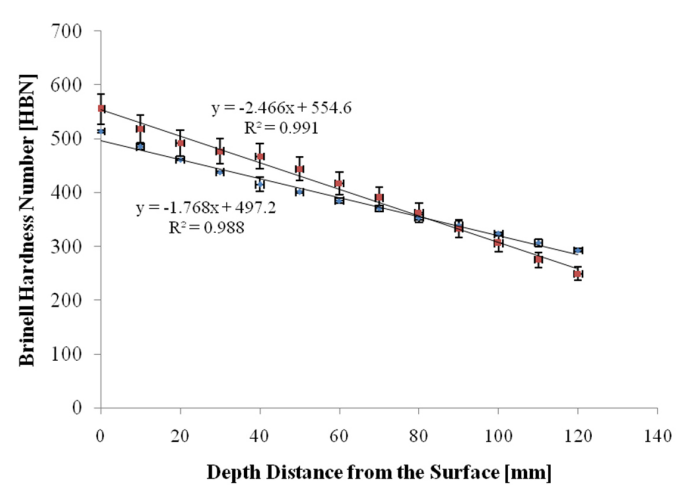

Figure 5. Hardness Value vs Depth for S and F4.

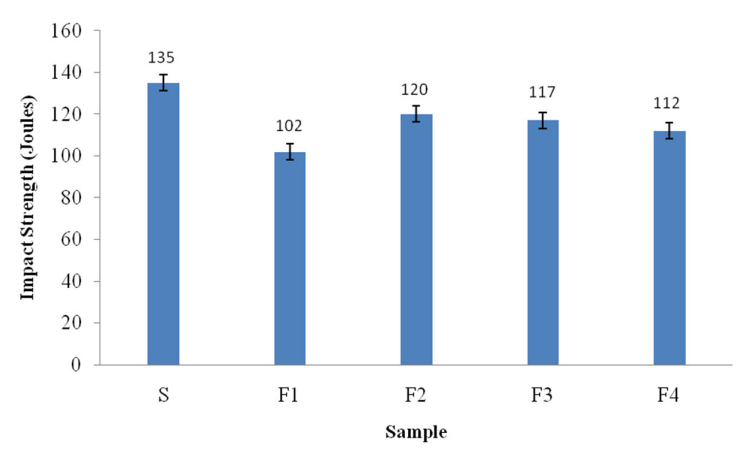

Figure 6. Impact Strength from Sample taken from Sound and Failed Crusher Jaws.

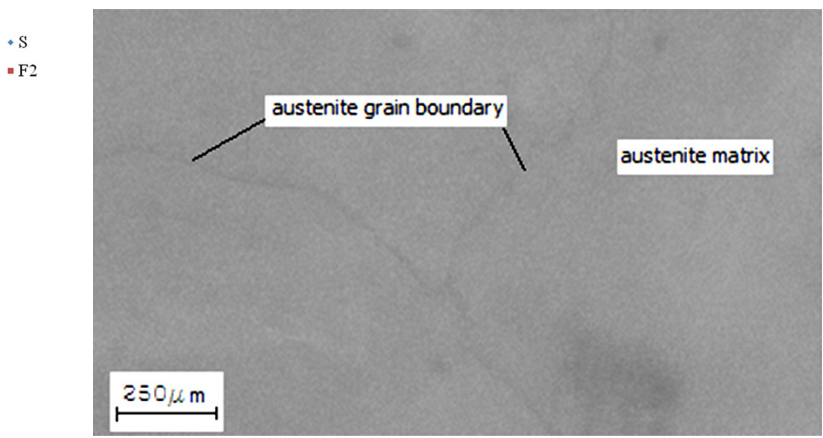

Figure 7. Optical micrograph of sample of sound crusher jaw(s) showing austenite grain boundaries in austenite matrix.

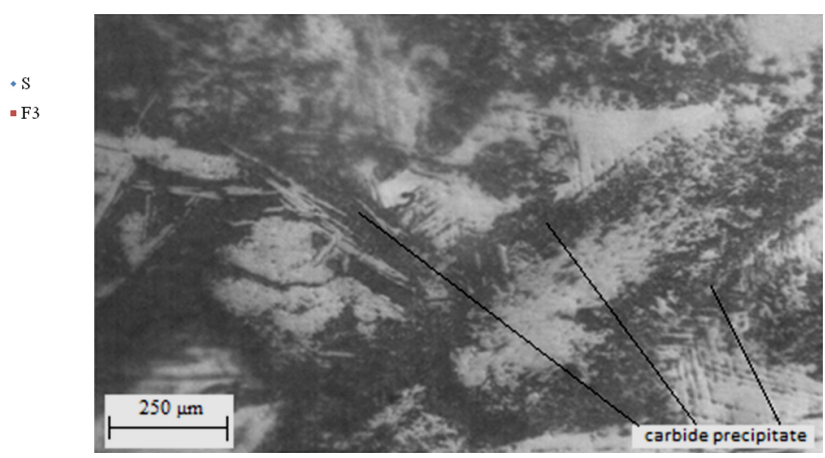

Figure 8. Optical micrograph of sample of failed crusher jaw $\left(F_{1}\right)$. The microstructure shows large carbides at austenite grain boundaries and in the grains of austenite matrix.

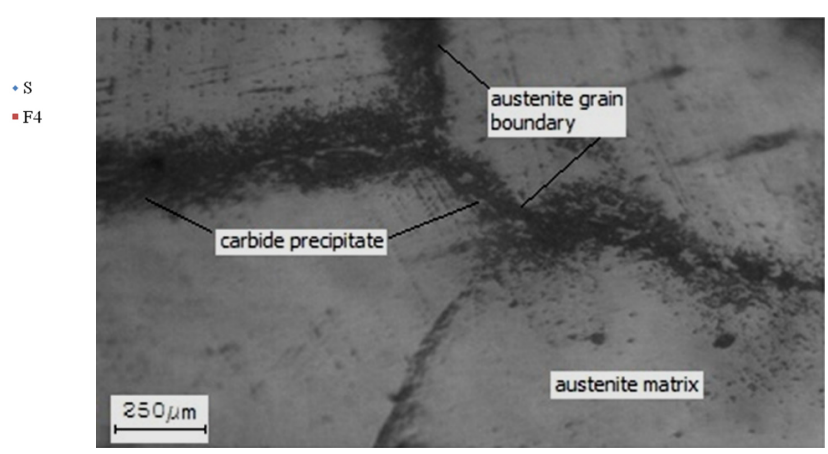

Figure 9. Optical micrograph of sample of failed crusher jaw $\left(\mathrm{F}_{2}\right)$. The microstructure shows large carbides at austenite grain boundaries.

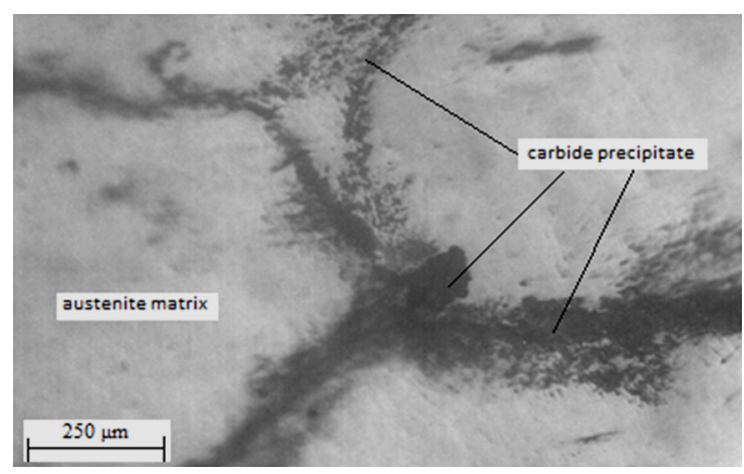

Figure 10. Optical micrograph of sample of failed crusher jaw $\left(\mathrm{F}_{3}\right)$. The microstructure shows large carbides that are mainly at austenite grain boundaries. 


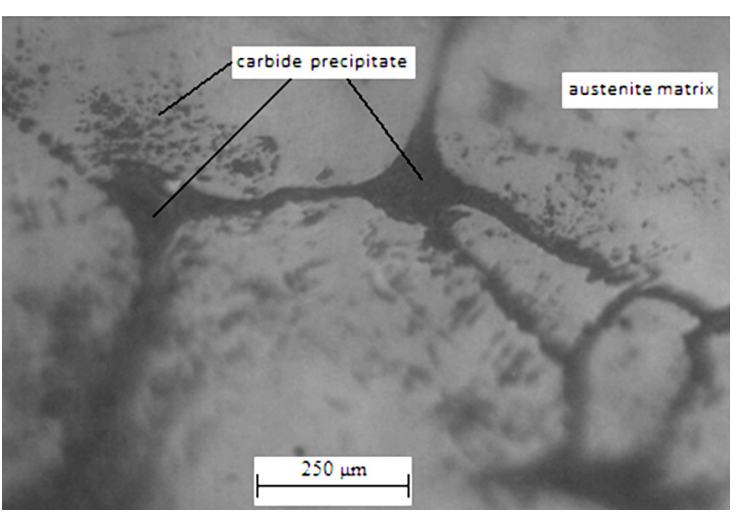

Figure 11. Optical micrograph of sample of failed crusher jaw $\left(\mathrm{F}_{4}\right)$. The microstructure shows large carbides, which are mainly at austenite grain boundaries and sparsely in the austenite matrix.

heat treated sample that was rapidly quenched in water bath without agitation revealed precipitation of carbide along the austenite grain boundaries (Figure 13). However, the heat treated sample that was rapidly quenched in agitated water revealed austenitic grains (Figure 14).

Alloying elements such as carbon, manganese and chromium in austenitic manganese steel increase wear resistance. The presence of these alloying elements in austenitic manganese steel can lead to the formation of cementite carbides, $(\mathrm{Fe}, \mathrm{Mn})_{3} \mathrm{C}$. These carbides possess very high hardness and increase the wear resistance in steels in proportion to the volume fraction of the carbide ${ }^{5,28}$. During autenitising, these carbides saturate the austenite and can result in a favourable condition for development or precipitation of carbides along the austenite grain boundaries and in the grains of austenite matrix. Because of the presence of these carbides, failed crusher jaws have a high value of hardness and low impact strength (Figures 2 to 6 ). The high impact strength coupled with low hardness value of the sound crusher jaw explains why it did not fail in service.

The presence of carbide at the grain boundaries corroborates the findings of Annette et al. which presented that boron in austenitic manganese steel leads to the formation of carboboride. This resulted in an increase in its abrasive wear resistance at the surface of the steel but impeded it at softer matrix ${ }^{36}$. The carbide precipitates have been found to play important roles in the hardness and abrasion resistance, and they also affect microstructure of austenitic manganese steel ${ }^{37,38}$. The presence, amount and dispersion of carbides have been found to significantly influence the wear resistance of austenitic manganese steel and impair its impact strength ${ }^{8}$. According to Allahkaram the precipitation of carbides along the grain boundaries act as a pre-existing crack path along which cracks initiate, propagate and failure eventually occur ${ }^{39}$.

In as-cast sample large clusters of carbides were detected along grain boundaries because of low cooling rate during solidification. Carbides are generally developed on grain boundaries and between dendrites during solidification. Solution treatment dissolves these carbides and quenching in agitated water produces a homogeneous austenitic structure.

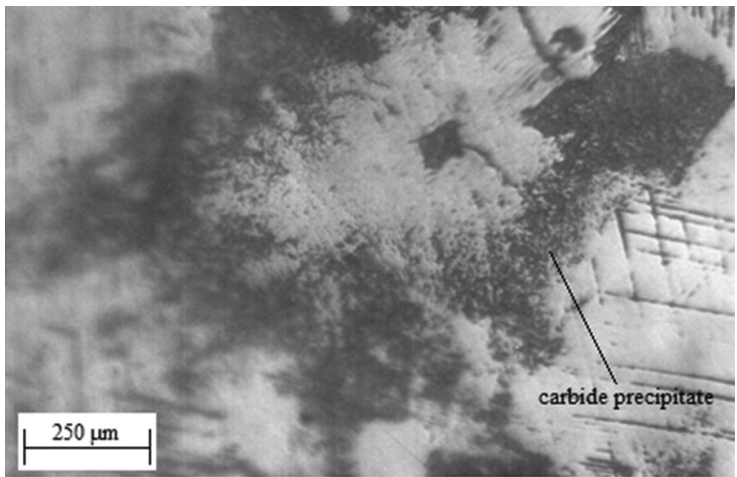

Figure 12. Optical micrograph of as-cast sample. The microstructure shows large carbides at austenite grain boundaries and in the grains of austenite matrix.

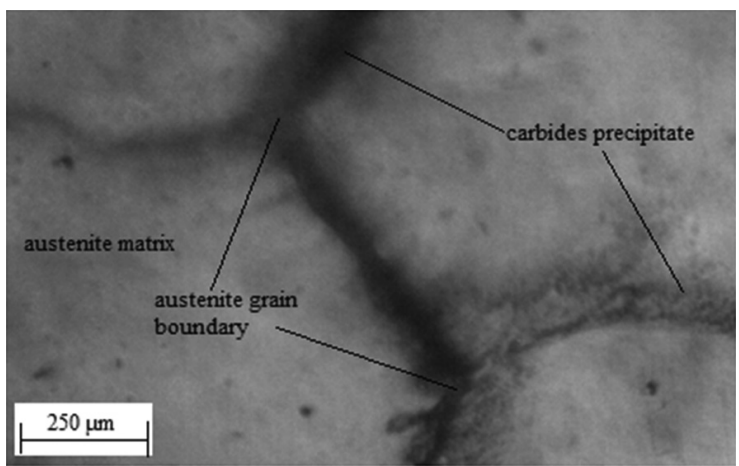

Figure 13. Optical micrograph of heat treated sample in water bath without agitation. The microstructure shows carbides precipitate along austenite grain boundaries.

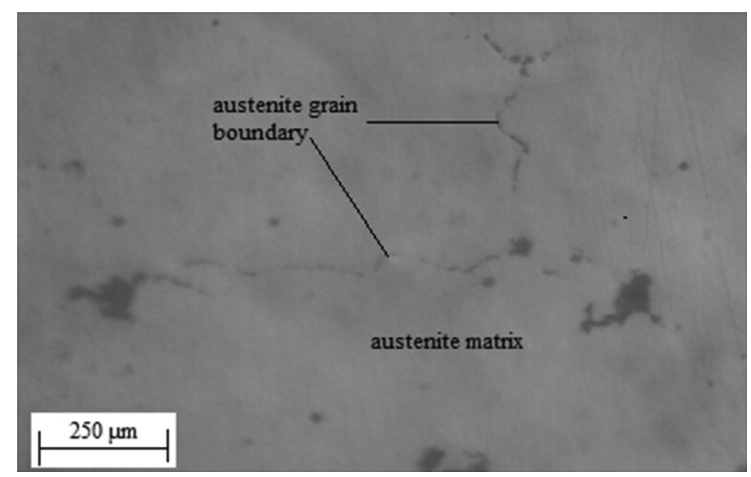

Figure 14. Optical micrograph of heat treated sample in agitated water bath. The microstructure shows austenite grain boundaries in austenite matrix.

However, cooling rate during quenching period in water bath without agitation is relatively low and given opportunity for carbide precipitation along the grain boundaries. Due to relatively low heat conductivity in this quenching method carbides precipitate as transgranular in the austenite matrix and grain boundaries as can be seen in Figures 8 to 11. As could be expected, cooling rate decreases with increment 
in section thickness while carbide volume increases with section thickness. This is in agreement with the work of Shabnam and Mohammad who stated that volume of carbide precipitate in austenitic manganese steel corresponds to its cooling rate ${ }^{29}$. Since the thermal history of failed crusher jaws indicates that they were quenched rapidly in water bath without agitation the different volume fractions of carbide observed in them can be attributed to their various section thickness (Figure 15).

The hardness at various depths attained by sound and various failed crusher jaw samples shown in Figures 2 to 5 confirmed that jaw crusher work hardened under the compressive action of crushing. Hardness is found to decrease inwardly from working surface to the core. This is because during impact blows, austenitic manganese steel develops surface hardness. However, the hardness values of sound crusher jaws changed gradually from the working surface to the core unlike the change in hardness values of failed crusher jaws (Figures 2 to 5). This means that austenitic manganese steels have the ability to harden inwardly in service but the extent of plastic flow and work hardening of sound crusher jaws is better than failed ones.

The hardness values of failed crusher jaw samples were higher than that of sound crusher jaws from the working surface to the depth of $95 \mathrm{~mm}$ while it is lower from depth of $50 \mathrm{~mm}$ to $120 \mathrm{~mm}$ (Figures 2 to 5). This hardness gradient indicates that there is no uniform plastic flow during work hardening of failed crusher jaws. The implication of this is that the failed crusher jaws did not combine the appreciable hardness and impact strength required for crushing (Figure 6). As a result of inadequate impact strength, failed crusher jaws were unable to withstand impact blows during crushing and hence failed by brittle fracture.

It was also observed that as the volume fraction of carbides precipitate in the grain boundaries and austenite matrix increased, hardness of the crusher jaws increased while the ability to withstand impact blow reduces. This observation is in line with the outcome of findings of Kuyucak and Zavadil which stated that the

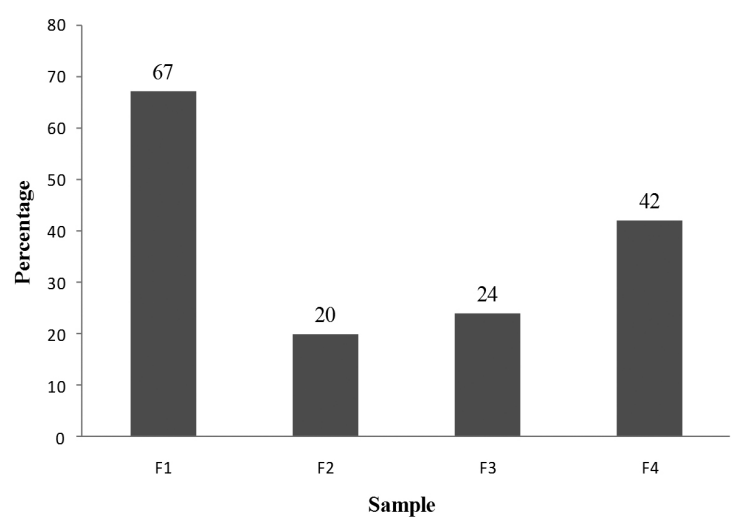

Figure 15. Percentage volume fraction of carbide precipitate. degree of embrittlement in austenitic manganese steels depends on the degree of grain boundary coverage by the embrittling phases and it is quantitatively related to impact toughness ${ }^{40}$. The volume fraction of carbide precipitate in sample $\mathrm{F}_{1}(67 \%)$ is more than $\mathrm{F}_{4}(42 \%), \mathrm{F}_{3}(24 \%)$ and $\mathrm{F}_{2}$ $\left(20 \%\right.$ ) in that order (Figures 8 to 11 ). In sample $F_{1}$ and $F_{4}$ the carbides precipitated are at both the grain boundaries and austenite matrix but it is sparsely concentrated in the austenite matrix in sample $F_{4}$. In sample $F_{2}$ and $F_{3}$ carbides only precipitated along the grain boundaries but the concentration is greater in sample $F_{3}$. This is the reason why the hardness value of samples $\mathrm{F}_{1}, \mathrm{~F}_{4}, \mathrm{~F}_{3}$ and $\mathrm{F}_{2}$ is higher than that of sample $\mathrm{S}$ from the working surface to the depth of $95 \mathrm{~mm} ; 85 \mathrm{~mm}, 50 \mathrm{~mm}$ and 65 $\mathrm{mm}$ respectively (Figures 2 to 5 ). The concentration of precipitated carbides also explains why the impact strength of $F_{1}$ is lower than $F_{4}, F_{3}$ and $F_{2}$ in that order (Figure 6). There is also correlation between the impact strength and the number of tonnage of rock crushed by crusher jaws before their eventual failure. As impact strength increases the run tonnage also increases (Figures 1 and 6).

From the analysis of the results obtained in this study it can be stated that the properties of austenitic manganese steel are greatly influenced by the heat treatment process. Solution treatment and quenching process should be properly controlled in order to obtain homogeneous austenitic structure. The solution temperature should be high enough to dissolve carbide precipitates formed during casting while the rate of heat conductivity during quenching should be high enough to prevent carbide precipitation. It can therefore be concluded that the crusher jaws failed as a result of low heat conductivity during the quenching operation that resulted in precipitation of carbides. The embrittling carbides minimize the impact strength of the crusher jaws and reduce their ability to absorb shock while crushing to the extent of volume fraction of precipitated carbide.

\section{Conclusion}

The failure of crusher jaws can be attributed to brittle fracture as a result of precipitates of carbides at the grains boundaries and in the grains. Inability of precipitated carbides to absorb shock under working conditions due to their embrittlement results in low impact strength of failed crusher jaws. The extent of concentration of these carbides determines the amount of embrittlement and the ability to withstand shock. It was also found that the hardness decreases inwardly from working surface to the core which indicates that crusher jaws work harden in service. However, there is no uniform plastic flow during work hardening of failed crusher jaws as compared with that of sound ones.

Finally, we conclude that the failure occurs as a result of inadequate quenching operation during manufacturing process that resulted in formation of carbide precipitates which embrittle the jaw crushers, reduce the ability to withstand shock and create a non uniform plastic flow during work hardening. 


\section{References}

1. Wiscers PF. Wear resistant steel. In: Steel casting handbook. Steel Founders Society of American; 1980. p. 1-17.

2. Ranjan TV, Sharma CP and Sharma A. Heat treatment principles and techniques. New Delhi: Prentice-Hall of India Private Limited; 1999.

3. Perry RH and Green DW. Solid-solid operation and processing. In: Chemical engineers handbook. 8th ed. New York: Mc Graw-Hill Companies; 2008. p. 56-61.

4. Subramanyan DK, Swansiger AE and Avery HS. Austenitic manganese steels. In: Metals Handbook. American Society of Metals; 1991. v. 1, p. 822-840.

5. Prabhudev KH. Handbook of heat treatment of steels. New Delhi: Tata Mc Graw Hill Publishing Company Limited; 1988.

6. Borik F and Sponseller DL. Gouging abrasion test for materials used in ore and rock crushing. ASTM Journal of Materials. 1971; 6:576-589.

7. Jing $\mathrm{T}$ and Zhang $\mathrm{F}$. The work hardening behaviour of medium manganese steel under impact abrasive wears condition. Materials Letter. 1997; 31(3-6):275-279. http://dx.doi. org/10.1016/S0167-577X(96)00293-5

8. Smith RW, DeMonte A and MacKay WBF. Austenitic manganese steel - developments for heavy haul rail transportation. Canadian Metallurgical Quarterly. 2003; 42(3):333-342. http:// dx.doi.org/10.1179/000844303794406099

9. Smith RW, DeMonte A and Mackay WBF. Development of high-manganese steels for heavy duty cast-to-shape applications. Journal of Materials Processing Technology. 2004; 153-154:589-595. http://dx.doi.org/10.1016/j. jmatprotec.2004.04.136

10. Li H, Zhihao J, Jinde L and Jun T. Modulated structure of Fe$10 \mathrm{Mn}-2 \mathrm{Cr}-1.5 \mathrm{C}$ alloy. Materials and Design. 2002; 23(8):717720. http://dx.doi.org/10.1016/S0261-3069(02)00072-9

11. Emin B, Frazal A, Khalid and Chritopher L. Deformation and fracture behaviour of high manganese austenitic steel. Journal of Materials Processing Technology. 2004; 147(2):145-154. http://dx.doi.org/10.1016/j.jmatprotec.2003.10.007

12. Canadinc D, Sehitoglu H, Maier HJ and Chumlyakor YI. Strain hardening behaviour of aluminium alloyed Hadfield steel single crystal. Acta Materialia. 2005; 53(6):1831-1842. http://dx.doi. org/10.1016/j.actamat.2004.12.033

13. Canadinc D, Sehitoglu H, Maier HJ, Niklasch D and Chumlyakor YI. Orientation evolution in Hadfield steels single crystals under combined slip and twinning. International Journal of Solids and Structure. 2007; 44(1):34-50. http:// dx.doi.org/10.1016/j.ijsolstr.2006.04.011

14. Efstathion $\mathrm{C}$ and Sehitoglu H. On the negative strain rate sensitivity of Hadfield steel. Scripta Materialia. 2008; 59(10):1103-1106. http://dx.doi.org/10.1016/j. scriptamat.2008.07.027

15. Efstathion $\mathrm{C}$ and Sehitoglu H. Strain hardening and heterogeneous deformation during twinning in Hadfield steel, Acta Materiala. 2009; 58(5):1479-1488. http://dx.doi. org/10.1016/j.actamat.2009.10.054

16. Dobrzanki LA, Grajcar A and Borek W. Microstructure evolution and phase composition of high manganese austenitic steel. Journal of Achievement in Materials and Manufacturing Engineering. 2008; 31(2):218-225.

17. Ravindra GT. Effect of frictional force and wear rate on Hardfield steel. International Journal of Engineering Research and Technology (IJERT). 2012; 1(6):1-7.
18. García A, Varela A, García L, Río MCS, Naya and Suárez M. Comparing the tribological behaviour of an austenitic steel subjected to diverse thermal treatments. Wear. 2005; 258:203207. http://dx.doi.org/10.1016/j.wear.2004.09.003

19. Yuan H, Xie J, Wang A, Wang W and Wang C. Plastic deformation wear in modified medium manganese steel. China Foundry. 2007; 4(3):194-197.

20. Yunhan X, Liang F, Qihong C and Jinhua Z. Subsurface microstructure evolution of Hadfield steel under impact energy. Materials Science Forum. 2005; 117:475-480.

21. Akeel DS and Omar AA. Phase transformations of Hadfield manganese steels. Engineering and Technology. 2007; 25(6):808-814.

22. Guo-Shang Z, Jian-Dong $X$ and Yi-Min G. Impact wear of WC/Hadfield steel composite and its interfacial characteristics. Wear. 2006; 260(7-8):728-734. http://dx.doi.org/10.1016/j. wear.2005.04.010

23. Wellin Y, Liang F, Kun S and Yunhua X. Effect of surface work harden on wear behaviour of Hadfield steel. Material Science and Engineering: A. 2007; 460-461:542-549. http://dx.doi. org/10.1016/j.msea.2007.02.094

24. Wellin Y, Liang F, Zhanguaga F, Kun S and Yunhua X. Effect of surface nanocrystallization on abrasive wear properties in Hadfield steel. Tribology International. 2009; 42(5):634-641. http://dx.doi.org/10.1016/j.triboint.2008.08.012

25. Majid A, Shahram K, Yousef K and Jalal H. On the comparison of the abrasive behaviour of aluminium alloyed and standard Hadfield steels. Wear. 2010; 268(1-2):202-207. http://dx.doi. org/10.1016/j.wear.2009.07.010

26. Kuyucak S and Zavadil R. On the heat treatment of Hadfield's austenitic manganese steels - Part II: metallographic studies. AFS Trans. 2000; 108:(00-126).

27. Jabłońska M, Śmiglewicz A, Niewielski G and Hetmańczyk M. Heat treatment of high manganese type X57MnA127-5. Materials Science and Engineering. 2011; 22: 1-6. http:// dx.doi.org/10.1088/1757-899X/22/1/012014

28. You-Soo H, Jeong-Tae K, Si-Young K, Jeong-Kil C and WooYoung Y. Critical cooling rate on carbide precipitation during quenching of austenitic manganese steel. China Foundry. 2010; 7(2):178-182

29. Shabnam H and Mohammad BL. Optimization of heat treatment to obtained desired mechanical properties of high carbon Hadfield steels. World Applied Sciences Journal. 2011; 15(10):1421-1424.

30. Sant SB and Smith RW. A study of work-hardening behaviour of austenitic manganese steel. Journal of Materials Science. 1987; 22:1808-1814. http://dx.doi.org/10.1007/BF01132410

31. Jackson W J and Hubbard M W. Steelmaking for steel founders. Sheffield: Steel Castings Research and Trade Association; 1979. p. 106.

32. Chakrabatti S. Cast austenitic manganese steels some practical notes. Available from: <www.cbgfoundry.com>. Access in: 18/01/2013.

33. American Society for Testing and Materials - ASTM. A128/ A128M - 93: Standard Specification for Steel Castings and Austenitic Manganese Steel. ASTM; 2007.

34. Olawale JO, Ibitoye SA and Shittu MD. A study of premature failure of crusher jaws. Journal of Failure Analysis and Prevention. 2011; 11(6):705-709. http://dx.doi.org/10.1007/ s11668-011-9511-7 
35. Ibitoye SA, Olawale JO and Shittu MD. Mechanical properties of quench-hardened, martempered and tempered ASTM A 128 grade B4 steel. Journal of Science and Technology (JUST). 2009; 29(2):107-117.

36. Annette G, Ingo S and Michael W. Gouging and sliding abrasion of austenitic manganese steels reinforced by hard phase. Proceeding of the International Conference on 'Wear of materials. 1987; 119(3):313-327.

37. Sallah SH, Omar MZ, Syarif J and Abdullah S. Carbide formation during precipitation hardening of SS440C steel. European Journal of Scientific Research. 2009; 34(1):83-91.
38. Jun W, Zhiping S, Baoluo S, Shengji G, Rulin Z, Cong L et al. Effects of secondary carbide precipitation and transformation on abrasion resistance of $16 \mathrm{Cr}-1 \mathrm{Mo}-1 \mathrm{Cu}$ white iron. Journal of Materials Engineering and Performance. 2006; 15(3):316-319. http://dx.doi.org/10.1361/105994906X108602

39. Allahkaram SR. Causes of catastrophic failure of high $\mathrm{Mn}$ steel utilized as crusher overlaying shields. IJE Transactions B: Applications. 2008; 21(1):55-64.

40. Kuyucak S and Zavadil R. On the heat-treatment of Hadfield's austenitic manganese steels, Part IV: microstructure vs. impact toughness relationship. AFS Trans. 2002; 110:1281-1298. 